\title{
Open-data presentation of a geophysical survey in Gerasa (Jerash), Jordan
}

Achim Lichtenberger ${ }^{1} \&$ Rubina Raja $^{2, *}$

This article presents data obtained in the first geophysical survey undertaken in the Decapolis city of Gerasa (Jerash) in northern modern Jordan, and reflects on the value of openly sharing data in the academic community.

Keywords: Middle East, Jordan, Gerasa, geophysical survey, open data sharing

\section{Introduction}

In 2011 the Danish-German Jerash Northwest Quarter Project, headed by the authors, together with the Eastern Atlas geophysical prospection company (Berlin), conducted a geophysical survey in the highest area within the walled Decapolis city of Gerasa (modern Jerash) in Jordan (Kraeling 1938; Lichtenberger \& Raja 2018a) (Figure 1). The survey was undertaken in preparation for excavations intended to investigate the settlement history of this unexplored part of the city. The geophysical survey covered approximately 4 ha using a fluxgate magnetometer system (Figure 2); three smaller test areas were surveyed using ground-penetrating radar (GPR). The results of the survey were published preliminarily in 2012 and are included in the final publication of the project (Kalaitzoglou et al. 2012; Pilz et al. in press). Both publications offer print-only maps, however, and only a selection of the full dataset-as is commonplace in archaeological publications. An open-data publication that makes the raw data available is therefore highly desirable; this would allow examples of best practice to be developed for future archaeological projects and open dialogues about the value of geophysical surveys within the framework of, and in combination with, other geographic and archaeological data. We have previously published open datasets combining lidar data with other geographical data such as earlier maps and non-georeferenced aerial photography. The results of this demonstrate that such an approach allows for a more integrated understanding of data and more detailed interpretation of it (Stott et al. 2018; Lichtenberger et al. 2019). The geophysical data from the Danish-German Jerash Northwest Quarter Project is published on a figshare server under a Creative Commons License (CC BY 4.0) (Lichtenberger \& Raja 2019a \& b). This allows other researchers to use, evaluate and integrate the raw data in their own projects freely.

The Northwest Quarter is situated on a natural karst limestone hill. The terrain slopes steeply to the north and south, and more gently to the east. Structures belonging to the ancient city are constructed of locally quarried limestone blocks. While fluxgate gradiometry

1 Institute of Classical Archaeology and Christian Archaeology, Archaeological Museum, Domplatz 20-22, Münster 48143, Germany

2 Department of Classical Studies and Centre for Urban Network Evolutions (UrbNet), Moesgård Allé 20, 8270 Højbjerg, Denmark

* Author for correspondence (Email: rubina.raja@cas.au.dk)

(C) Antiquity Publications Ltd, 2019

ANTIQUITY 93 371, e31 (2019): 1-7

https://doi.org/10.15184/aqy.2019.157 


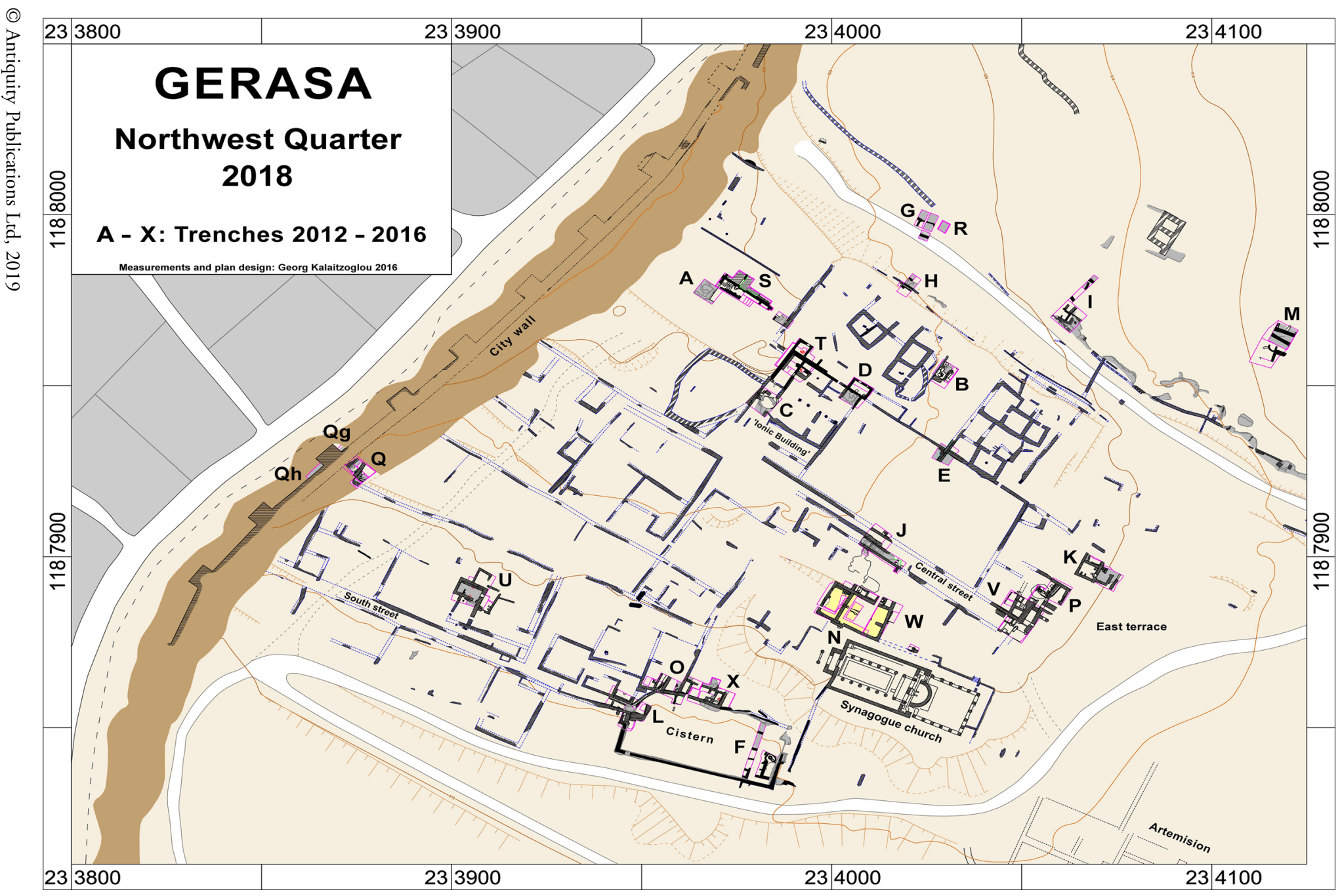

Figure 1. Plan of the Northwest Quarter of Jerash (@ Danish-German Jerash Northwest Quarter Project). 


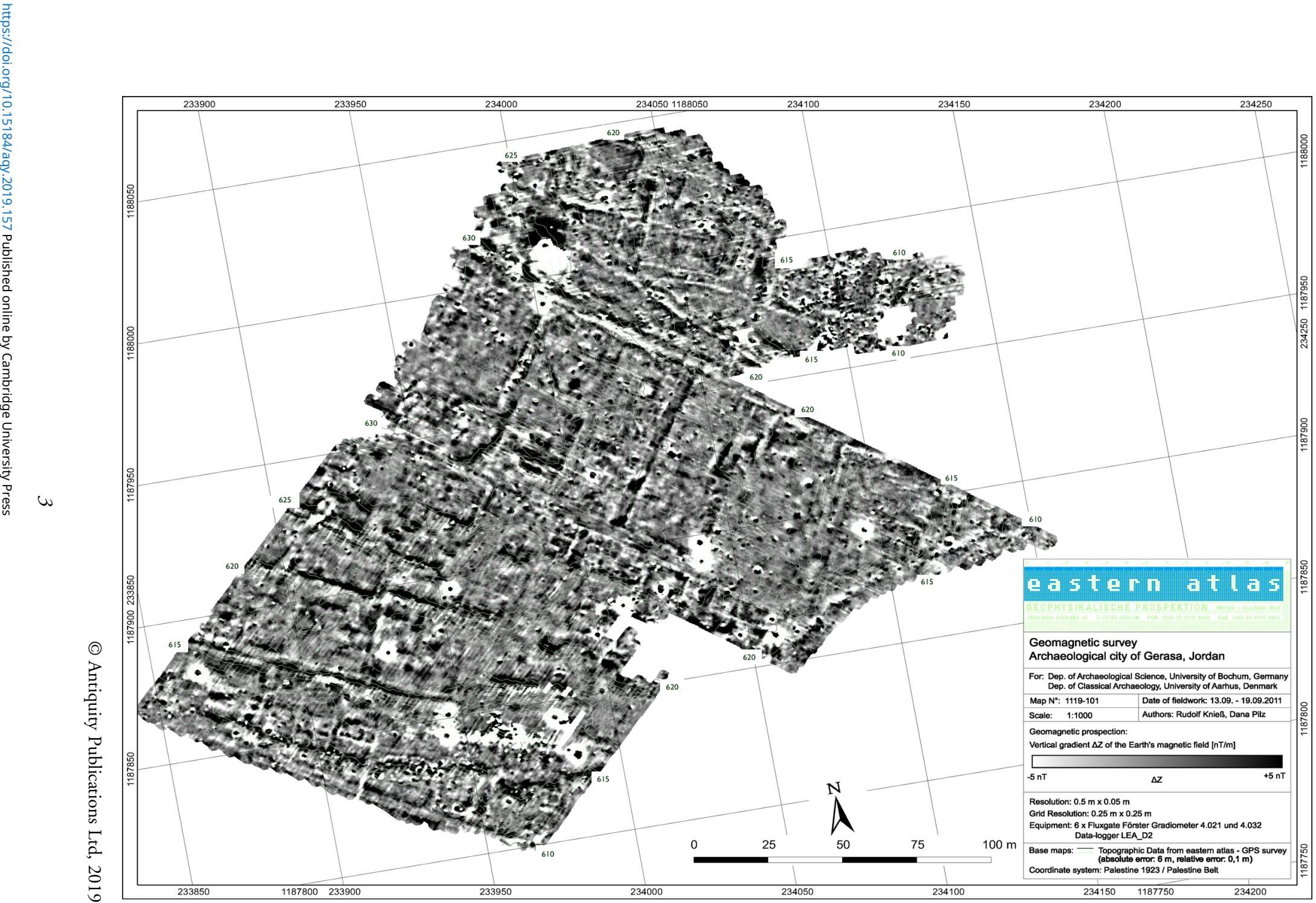

Figure 2. Map of the magnetic results in greyscale with threshold values of $\pm 5 n T$ (@ Danish-German Jerash Northwest Quarter Project).

Project Gallery 
produced good results, GPR was only effective to a limited extent due to the geology, soil and surface conditions of the site. As Gerasa is a dynamic multi-period site, and the Northwest Quarter was densely settled until the end of the Umayyad period, the fluxgate magnetometer maps display numerous anomalies and structures (Figure 3). Interpretation of this data is not the aim of this paper, however, and survey results relating to the chronology of the settlement have been published elsewhere (Lichtenberger \& Raja 2015, 2017, 2018b).

\section{Applied geophysics}

The applied geophysical techniques are presented in detail here to show how results were obtained. For the magnetic investigations, an array of six fluxgate gradiometer probes, carried by the geophysicist, was used (Figure 4) (cf. Kalaitzoglou et al. 2012; Pilz et al. in press). This made it possible to cover the entire Northwest Quarter including steep slopes and areas of dense building and debris. The probes registered the vertical gradient of the vertical magnetic field component with an accuracy of $0.1 \mathrm{nT}$ (nanotesla). The measured gradient is insensitive to the typical large fluctuations of Earth's magnetic field and is determined only by the magnetisation of local anomalies in the ground. Data-processing consisted of an offset shift and a drift correction. Drift correction is necessary because the sensors are subject to internal thermal drift, which can affect the calibration of the instrument. The resulting map of the magnetic investigation is shown in Figure 2.

For the GPR, a GSS Inc. SIR-3000 GPR system with a $270 \mathrm{MHz}$ antenna was used. GPR was applied in three locations with relatively level ground. Due to soil conditions, the electromagnetic waves did not penetrate deep into the surface, however; consequently, the resulting GPR profiles provide minor reflections only (see Pilz et al. in press). The reason for the poor penetration and low reflectivity of the targets was most likely similarities between the bedrock and construction materials, and the thin but dry and clay-rich topsoil. The vertical profiles of the GPR data were transformed into horizontal sections. Processing comprised static corrections in order to estimate precise depth and enhance the signal-to-noise ratio. The GPR data is available at three depths from $0 \mathrm{~m}$ to a maximum depth of $1.5 \mathrm{~m}$, from which an average is calculated. Each section represents a time interval of 10ns (nanoseconds), which reflects the two-way transit time. The physical layer thickness of approximately $0.5 \mathrm{~m}$ results from an estimation of the average electromagnetic wave propagation velocity of $\mathrm{v}=0.1 \mathrm{~m} / \mathrm{ns}$.

\section{Best practice in archaeology: open-data strategies}

While geophysical surveys have become integral parts of archaeological projects and are often undertaken prior to excavation, the data collected are rarely made available openly. There are several reasons for this, such as space restrictions or unwillingness to share data openly, and the result is that although we can see the interpretation of results, we cannot truly learn from the experiences of the teams. If other archaeologists cannot access the raw data, they are not able to reinterpret them or use them to simulate alternative results. Nor can they implement the same methodologies in on-going or new fieldwork. We cannot learn from them in a reflective way. Furthermore, space restrictions in printed media mean that larger datasets, such as those obtained from geophysics, are often published selectively. For effective interpretations, however, a combination of several magnetograms at a range of resolutions is (C) Antiquity Publications Ltd, 2019 


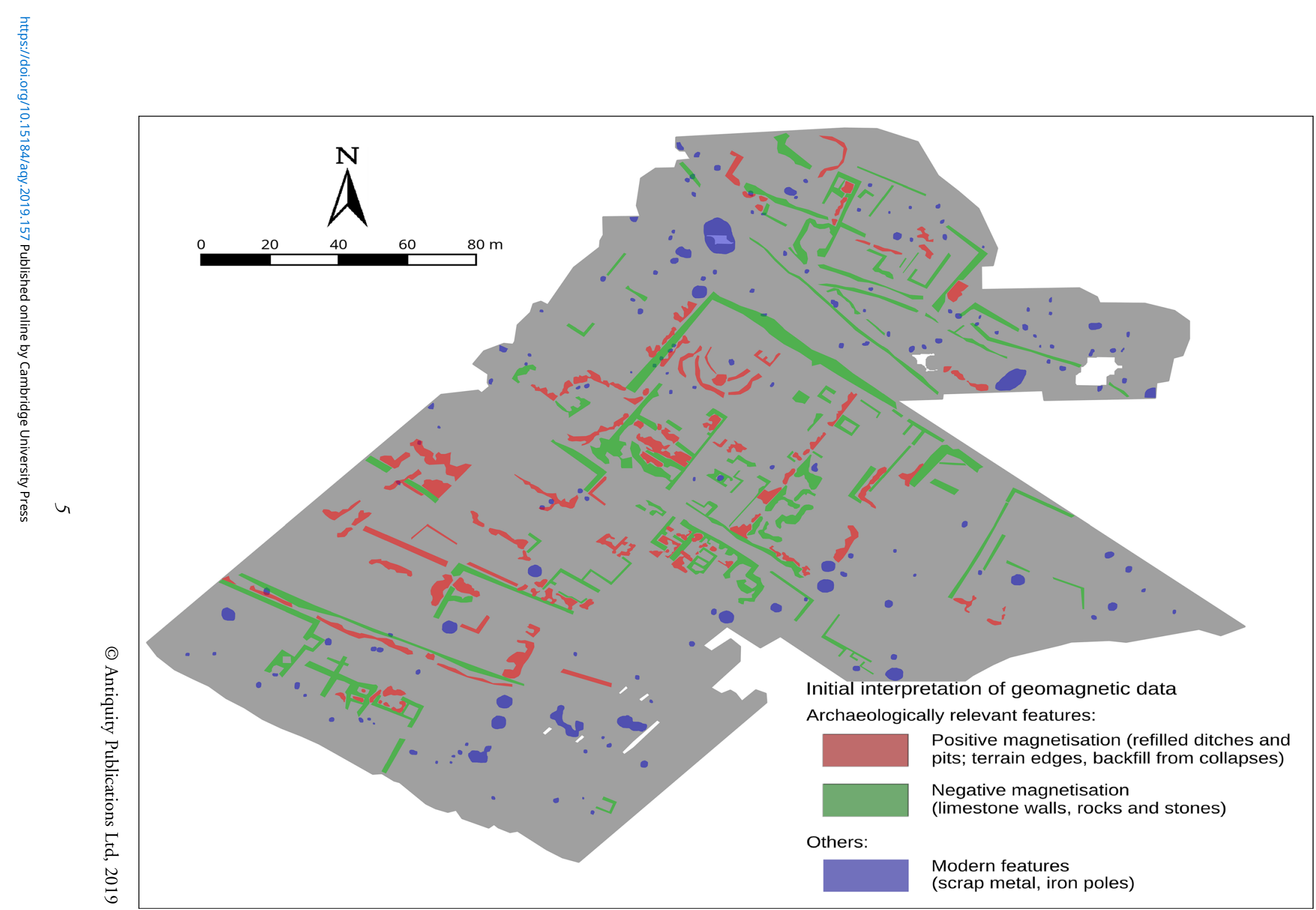

Figure 3. Interpretation of the magnetic results (() Danish-German Jerash Northwest Quarter Project).

\section{Project Gallery}




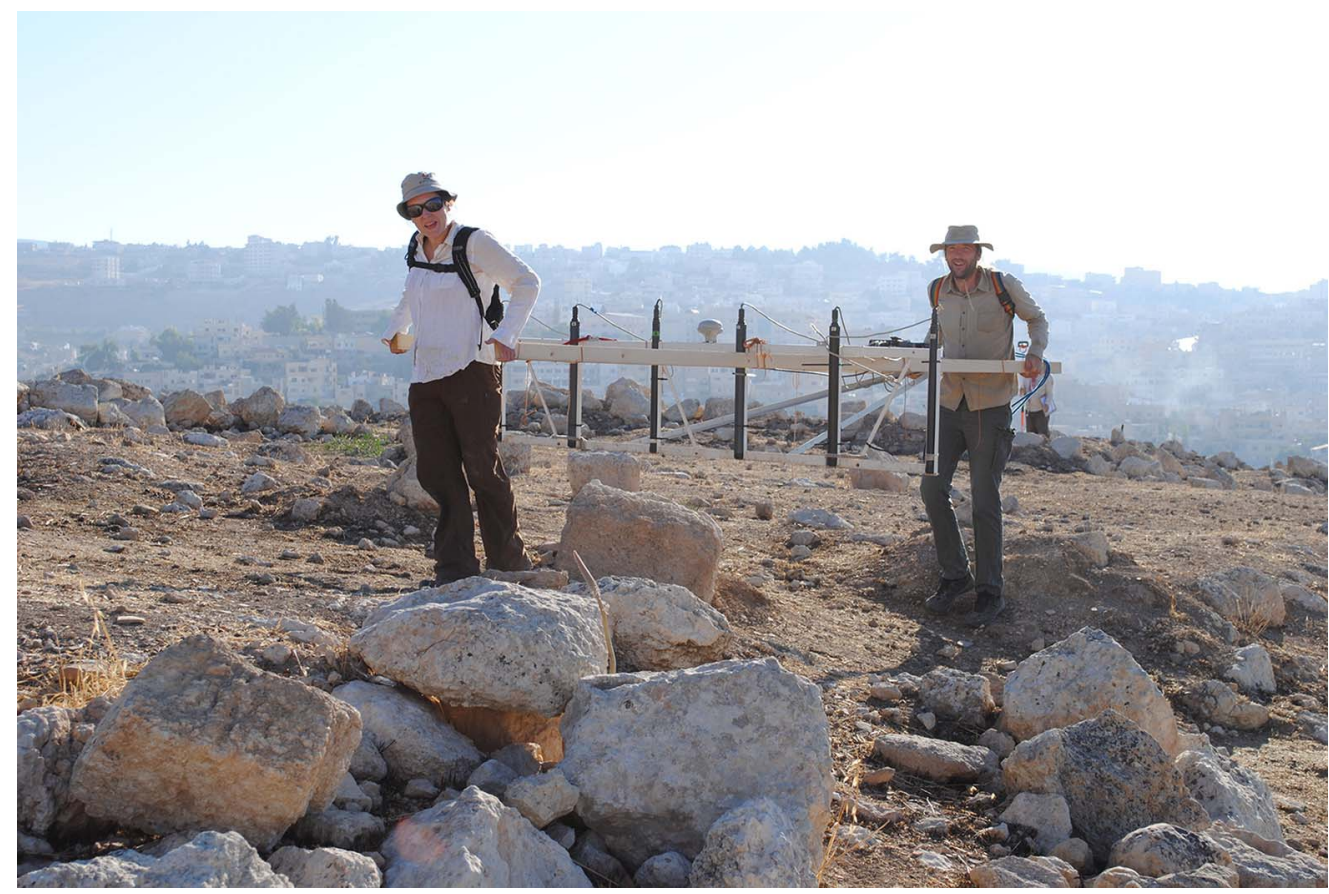

Figure 4. Fluxgate gradiometer in action in the Northwest Quarter (CDanish-German Jerash Northwest Quarter Project).

necessary. Georeferenced data maps of fluxgate gradiometry surveys at a range of nT resolutions should be made accessible to the wider research community; this is crucial to allow for a more holistic understanding of sites and to enable integration of existing results into future research. It would also allow other researchers to review geophysical data and to reflect critically on methodologies in order to raise the standard of best practice continually. This practice is also valid for unsuccessful data-gathering such as the aforementioned attempt to use GPR at Gerasa. Data from techniques that have not yielded important archaeological results are rarely published. Presenting such data openly, however, can inform future research and improve fieldwork methods. Providing geophysical data in an open-data format is a conditio sine qua non if we are to make data usable and sustainable in the long term (Wilkinson et al. 2016).

\section{Acknowledgements}

The authors would like to thank Eastern Atlas, in particular Dana Pilz and Rudolf Knieß, for their excellent cooperation in the project as well as technical descriptions. We also thank our funding bodies: The Carlsberg Foundation; the Danish National Research Foundation (grant 119); Deutsche Forschungsgemeinschaft; Deutscher Palästina-Verein; the EliteForsk initiative of the Danish Ministry of Higher Education and Science; and H.P. Hjerl Hansens Mindefondet for Dansk Palæstinaforskning.

\section{References}

Kalaitzoglou, G., R. Kniess, A. Lichtenberger, D. Pilz \& R. Raja. 2012. Report on the

(C) Antiquity Publications Ltd, 2019 geophysical prospection of the northwest quarter of Gerasa/Jerash 2011. Annual of the Department of Antiquities of Jordan 56: 79-90. 
Kraeling, C.H. 1938. Gerasa. City of the Decapolis. New Haven (CT): American Schools of Oriental Research.

Lichtenberger, A. \& R. Raja. 2015. New archaeological research in the Northwest Quarter of Jerash and its implications for urban development of Roman Gerasa. American Journal of Archaeology 119: 483-500. https://doi.org/10.3764/aja.119.4.0483

- 2019a. Jerash Northwest Quarter GPR data. Available at:

https://figshare.com/articles/

Jerash_Northwest_Quarter_GPR_data/8262020 (accessed 12 September 2019).

- 2019b. Jerash Northwest Quarter GPR data. Available at:

https://figshare.com/articles/

Jerash_Northwest_Quarter_magnetic_data/ 8277248 (accessed 12 September 2019).

Lichtenberger, A. \& R. RajA (ed.). 2017. Gerasal Jerash: from the urban periphery. Aarhus: Fællestrykkeriet AUTRYK.

-2018a. The archaeology and history of Jerash. 110 years of excavations (Jerash Papers 1). Turnhout: Brepols.

Lichtenberger, A. \& R. Raja 2018b. A view of Gerasa/Jerash from its urban periphery: the
Northwest Quarter and its significance for the understanding of the urban development of Gerasa from the Roman to the Early Islamic period, in A. Lichtenberger \& R. Raja (ed.) The archaeology and history of Jerash. 110 years of excavations (Jerash Papers 1): 143-66. Turnhout: Brepols.

Lichtenberger, A., R. Raja \& D. Stott. 2019. Mapping Gerasa: a new and open data map of the site. Antiquity Project Gallery 93(367). https://doi.org/10.15184/aqy.2019.9

Pilz, D., R. Kniess, A. Lichtenberger \& R. Raja. In press. Geophysical data and archaeological evidence: a comparative interpretation, in A. Lichtenberger \& R. Raja (ed.) Danish-German Jerash Northwest Quarter Project. Final publications volume 1 (Jerash Papers 6). Turnhout: Brepols.

Stott, D., S.M. Kristiansen, A. Lichtenberger $\&$ R. RAJA. 2018. Mapping an ancient city with a century of remotely sensed data. Proceedings of the National Academy of Sciences of the USA 115. https://doi.org/10.1073/pnas.1721509115

Wilkinson, M.D. et al. 2016. Comment: the FAIR guiding principles for scientific data management and stewardship. Nature Scientific Data 3.

Received: 9 May 2019; Revised: 14 June 2019; Accepted: 21 June 2019 